\title{
Adolescência e violência: mais uma forma de exclusão
}

\author{
Feizi M. Milani
}

\begin{abstract}
RESUMO
O presente ensaio se propõe a discutir algumas das interfaces entre a questão da violência e a fase da adolescência na sociedade brasileira contemporânea. $\mathrm{O}$ texto traz em destaque a complexidade das causas e manifestações da violência, com ênfase nos contextos da família e da escola. A partir de uma revisão de dados epidemiológicos, o autor pontua diferentes manifestações do fenômeno da exclusão e sinaliza possíveis estratégias de prevenção à violência cometida por, contra e entre adolescentes.

Palavras-chave: adolescência, violência, prevenção.
\end{abstract}

\begin{abstract}
This paper aims at discussing some interfaces of the issue of violence and teenagers' place in Brazilian contemporary society. The complexity of causes and its violence is emphasized, particularly in family and school contexts. From a revision of epidemiological data, different analyses of the exclusion phenomenum are presented and possible strategies to prevent violence against and among adolescents are suggested.

Key-words: adolescence, violence, prevention.
\end{abstract}

\section{Introdução}

O presente ensaio se propõe a discutir algumas das interfaces entre a questão da violência e a fase da adolescência na sociedade brasileira contemporânea. A violência, em suas inúmeras modalidades e expressões, vem se tornando, em anos recentes, um dos problemas que mais angustia esta sociedade, quer seja devido à divulgação de fatos do cotidiano ou dados estatísticos, ou a uma sensação difusa de insegurança e desconfiança que se propaga. Institui-se, assim, um círculo vicioso no qual "a violência gera o medo, mas este gera igualmente a violência", numa escala que pode chegar ao grau de "psicose coletiva" (CHESNAIS, 1999).

Em várias partes do mundo, inclusive nas Américas e no Brasil, a violência alcança tamanha disseminação, magnitude e freqüência que passa a ser reconhecida como um grave problema de Saúde Pública, cujas conseqüências não se limitam às crescentes taxas de mortalidade, mas englobam seqüelas biopsicossociais e morais em nível pessoal, familiar e coletivo (YUNES; RAJS, 1994).

O fenômeno da violência, em sua complexidade e multicausalidade, tem engolfado também a adolescência. Os adolescentes, ao se envolverem com a violência, quer na condição de vítimas ou na de perpetradores, terminam por sofrer alguma forma de exclusão. Quando vitimados, ocorre a exclusão da própria vida ou do "estado de completo bem-estar físico, mental e social". Quando agressor, o adolescente é excluído da possibilidade de viver em exercício da cidadania, por meio da qual pode reconhecer-se e ser reconhecido como sujeito de direitos e deveres.

\section{Alguns dados epidemiológicos}

No Brasil, em 1996, 35,1\% das mortes de jovens foram provocadas por homicídios e outras violências, percentual este que atingiu $47,7 \%$ nas regiões metropolitanas do país - (praticamente a metade!). Ao comparar o número de 15.288 jovens assassinados com os 1.199 óbitos decorrentes da Aids (2,8\% da mortalidade juvenil) - em 1996 - WAISELFISZ (1998) denuncia que, para "um mal 13 vezes maior que a Aids, são ainda escassas e bastante tímidas as ações e políticas de enfrentamento". 
Tais números colocam o Brasil num vergonhoso $3 .^{\circ}$ lugar no mundo em mortes de jovens por homicídios e outras violências, com uma taxa de óbito de 48,6 por 100.000 jovens (WAISELFISZ, 1998). Certamente, não é coincidência que o Brasil seja conhecido como o país com a pior distribuição de renda, leia-se violência estrutural. Embora seja equivocada a "associação mecânica entre violência, pobreza, criminalidade e violação dos direitos, predominante no senso comum" (GOMES; SILVA; NJAINE, 1999), é perceptível que as desigualdades econômicas e a miséria estão diretamente relacionadas com as taxas de homicídio e com a violência não gratuita (MCALISTER, 1998).

A violência tem atingido diretamente a juventude brasileira, de modo que o principal grupo de risco para a mortalidade por homicídio "são adolescentes e adultos jovens, do sexo masculino [...] residentes em áreas pobres e às vezes periféricas das grandes metrópoles; de cor negra ou descendentes dessa etnia; com baixa escolaridade e pouca ou nenhuma qualificação profissional" (MINAYO; SOUZA, 1999). Em Salvador, a sobremortalidade masculina alcança o valor de 12,7 na faixa de 15 a 19 anos (PAIM; COSTA, 1996). Freqüentemente, no entanto, "os violentados passam a ser encarados como os violentos" (NETO; MOREIRA, 1999). Não obstante, contrariando o senso comum, 70,7\% dos adolescentes e jovens vítimas de execuções em São Paulo não estavam implicados em crime anterior e $67,1 \%$ possuíam profissão/ocupação ou eram estudantes (MESQUITA, 1995). Os preconceitos acrescem, portanto, exclusão moral à econômica na vida desses adolescentes.

O homicídio representa, no quadro da violência, a porção mais visível e irreversível. Estima-se que, para cada morte violenta, ocorrem pelo menos 100 casos de injúrias não fatais provocadas pela violência (U.S. DEPARTMENT OF JUSTICE, 1988), os quais permanecem, em sua maioria, encobertos. No período de um ano, 200.000 crianças e adolescentes declararam-se vítimas de agressão física (IBGE, 1989). Adolescentes que foram vítimas de violência em sua infância carregam o mais alto risco de se tornarem perpetradores de violência (MCALISTER, 1998), o que realça a importância de programas de prevenção.

A outra vertente na relação entre juventude e violência é evidenciada pelo constante aumento do número de adolescentes envolvidos com gangues, o crime organizado e/ou atos violentos: “em 1997, no Rio de Janeiro, 354 menores de 14 anos foram detidos pelo Juizado por cometerem atos delinqüentes; em São Paulo, 15\% dos suspeitos detidos pela Polícia Militar tem idade entre 12 e 17 anos" (Programa Nacional de Paz nas Escolas, 1999).

Ao longo da história e em grande parte dos povos, a adolescência tem sido identificada com os níveis mais elevados de agressividade, transgressão e conflito. Autores como Dahrendorf e Holinger estabelecem uma relação direta entre juventude e violência. Se suas premissas estiverem corretas, podemos considerar sombrias as perspectivas da sociedade brasileira nos próximos dez a quinze anos. O perfil demográfico do Brasil está iniciando uma "onda adolescente", durante a qual esse grupo etário tornou-se o mais numeroso da população. São mais de 34 milhões de adolescentes, representando mais de $20 \%$ da população, o que "vai impor grandes mudanças no país" por suas demandas em relação ao sistema de ensino, mercado de trabalho, lazer e cultura (JUNQUEIRA, 1997).

O panorama acima descrito não diz respeito apenas a fenômenos isolados. São atos que manifestam um "estado de violência" (NUNES, 1999), o qual institui "mecanismos de negação da cidadania" (WAISELFISZ, 1998) e denuncia modos de sociabilidade e circunstâncias políticas e econômicas nas quais a violência prospera.

\section{O desafio da desconstrução da violência}

Nunca é demais relembrar que "é, hoje, praticamente unânime [...] a idéia de que a violência não faz parte da natureza humana e que a mesma não tem raízes biológicas" (MINAYO, 1994). A violência trata-se de um "fenômeno histórico-social, construído em sociedade", portanto, "pode ser desconstruída" (MINAYO, 1999).

A desconstrução da violência exige o envolvimento dos sujeitos, das instituições e da sociedade, em suas multidimensionalidades - física, mental, emocional, ética, espiritual, econômica, jurídica, política etc. $\mathrm{O}$ sistema educacional tem uma responsabilidade especial nesse processo. Se, por um lado, é fundamental não ceder à tentação de colocar a responsabilidade pela transformação da sociedade nos ombros da educação ou de considerar que as injustiças socioeconômicas poderão ser solucionadas por um ensino de qualidade, por outro lado, é inegável o papel crucial que desempenha na formação intelectual e moral das novas gerações. 
Um dos fatores para que os adolescentes tenham sido engolfados nessa trama da violência é a dificuldade de pais, profissionais de educação e de saúde, e governantes em compreenderem as características e necessidades dessa etapa. A adolescência é marcada por profundas transformações nas quais se entrelaçam processos de amadurecimento físico, mental, emocional, social e moral, que são influenciados pelas peculiaridades inerentes a cada sujeito, pelo seu ambiente sociocultural e pelo momento histórico, o que torna complexa a sua delimitação ou conceituação (OSÓRIO, 1989; COSTA, 1999) .

ERIKSON (1976) compara a adolescência a uma "moratória psicossocial" devido à "confusão de identidade" que se estabelece nessa fase:

inevitável num período da vida em que o corpo muda radicalmente suas proporções, em que a puberdade genital inunda o corpo e a imaginação com toda espécie de impulsos, em que a intimidade com o outro sexo se aproxima [...] e em que, enfim, o futuro imediato [...] coloca (a pessoa) diante de um número excessivo de possibilidades e opções conflitantes.

Tal crise gera no adolescente a necessidade de formar grupos, "estereotipando-se a si próprios, aos seus ideais e aos seus inimigos", podendo tornar-se "intolerantes e cruéis na sua exclusão de outros que são "diferentes", como uma forma de defesa contra esse sentimento de perda de identidade (ERIKSON, 1976). Nesses casos, o adolescente torna-se agente de exclusão, sob o risco de grupos rivais se engalfinharem numa escalada de agressões mútuas por motivos banais.

Essa fragilidade interior do adolescente, muitas vezes mascarada sob atitudes agressivas e de desdém pelo outro, é uma das causas de sua vulnerabilidade a tantos fatores de risco - álcool, drogas, DST/Aids, violência etc. Isto apenas intensifica a responsabilidade da família e da escola, componentes fundamentais do contexto do desenvolvimento do adolescente (BRONFENBENNER, 1996), no sentido de promoverem os fatores protetores de seu bem-estar. É através das interações que os agentes de socialização - pais, educadores transmitem crenças e práticas veiculadas no meio social ao qual pertencem que são essenciais para a constituição do sujeito. A cultura adquire, assim, a função de organizadora das práticas educativas (BASTOS, 1994).

\section{Família, a primeira escola}

Embora existam múltiplas formas de família em nossa sociedade, distintas dos moldes tradicionais, o fato é que, independente de sua estrutura, a família é o primeiro grupo, a primeira escola, a primeira comunidade e a primeira experiência de exercício da cidadania que todo indivíduo vivencia, sendo essa experiência profundamente marcante e, muitas vezes, determinante da trajetória de vida. No entanto, como "laços de consangüinidade não asseguram o amor" (SAFFIOTI, 1989), freqüentemente o convívio familiar é marcado pela violência doméstica - cujas principais vítimas são crianças, adolescentes e mulheres.

A violência doméstica contra crianças e adolescentes é caracterizada pelo abuso do poder disciplinar e coercitivo de pais ou responsáveis, que muitas vezes se prolonga ao longo de meses e anos, sendo uma violação dos direitos essenciais da criança e do adolescente em sua condição de humanidade (AZEVEDO, 1997). Pode apresentar-se na forma de violência física, psicológica, sexual ou negligência/abandono.

As modalidades intrafamiliares de violência são marcantemente complexas, dentre outros, pelos seguintes fatores:

a) A definição exata do que constitui ou não violência na relação entre pais e filhos é controversa e complexa, sendo permeada por padrões culturais.

b) A mensuração da violência psicológica (que implica em rejeitar, isolar, aterrorizar, ignorar, corromper ou criar expectativas exageradas) é tarefa extremamente difícil.

c) Os dados sobre a violência doméstica são escassos, principalmente em nosso país, onde ainda impera a "lei do silêncio".

d) Em geral, os adolescentes que sofrem violência doméstica não a interpretam como um problema mas, sim, como um direito natural dos pais ou algo normal na linguagem familiar.

A despeito dessa "naturalização da violência", sabe-se que a maioria dos jovens infratores testemunhou e foi vítima de violência doméstica. Essa experiência pode afetar a forma do adolescente interpretar a realidade, encarando como provocação pessoal situações banais. Também tende a limitar o seu 
repertório de reações a comportamentos violentos. A combinação desses dois fatores aumenta expressivamente o risco do jovem se envolver em brigas e, eventualmente, em atos delituosos.

Um aspecto pouco discutido da questão é relativo às mães adolescentes. A maioria delas carece de experiência e de maturidade psicológica, muitas não desejaram, ao menos conscientemente, a gravidez; outras se vêem privadas da liberdade que usufruíam antes - fatores esses que podem levar a situações de maus tratos com seus filhos.

Outra modalidade de violência que, embora não sendo exclusiva do âmbito doméstico, é nele que ocorre com maior freqüência, é a violência contra a mulher. Em distintas partes do mundo, entre 16 e $52 \%$ das mulheres experimentam violência física de parte de seus parceiros (OPAS, 1998). Apesar disso - ou exatamente por esse motivo - a violência de gênero é ainda marcada pela "invisibilidade social". Esta violência diz respeito a "sofrimentos e agressões dirigidos especificamente às mulheres pelo fato de serem mulheres" (SCHRAIBER; D’OLIVEIRA, 1999).

Uma vez que metade dos adolescentes pertence ao sexo feminino, é estarrecedor o impacto estatístico e social das discriminações, abusos físicos, psicológicos e sexuais por elas sofrido. A título de exemplo, estima-se que, no Brasil, em 1985, uma em cada cinco meninas tenha sofrido abuso sexual, sendo que 300.000 (5\% daquele total) foram vítimas de incesto pai-filha, das quais 38\% tentarão suicídio (AZEVEDO; GUERRA, 1997).

Em relação aos rapazes, pode-se constatar que são submetidos a uma "automutilação [por terem que] reprimir as partes de sua própria personalidade consideradas femininas" (GIFFIN, 1994). Além disto, "o valor cultural da honra masculina" (ZALUAR, 1993) gera a necessidade de comprovação da virilidade através de demonstrações de força física, valentia, enfrentamento de perigos e brigas, aumentando os riscos de sofrerem ou praticarem violência. Apesar disto, raramente os projetos de investigação e intervenção incluem também os homens.

A violência de gênero, quando ocorre na relação conjugal, atinge também os filhos, que se tornam testemunhas freqüentes e impotentes ou, até mesmo, vítimas de maus tratos por tentarem defender a mãe. Apesar de todo sofrimento que passam, um expressivo percentual desses filhos repete, em sua vida adulta, o mesmo padrão de relacionamento, por haver interiorizado esse modelo de opressão, agressão e medo.

\section{Interações entre vida familiar e escolar}

Ao entrar na escola, a criança já traz consigo um conjunto único de características pessoais, experiências de vida, capacidades já desenvolvidas e potencialidades. Aquelas crianças cujo ambiente familiar é marcado pela violência entre os pais ou contra elas "tendem a ser agressivas e a ter comportamentos antisociais fora de casa, principalmente na escola". Se além da violência doméstica essas crianças ou adolescentes são testemunhas ou vítimas de violência em seu bairro, as conseqüências se agravam:

\footnotetext{
... [elas] têm mais dificuldades de leitura e compreensão de textos [...], menor capacidade de atenção e concentração em tarefas [...], são ainda mais apáticas, desinteressadas pelas normas. Têm mais problemas disciplinares, mais suspensões, piores notas, repetências [...] $\mathrm{O}$ mau desempenho escolar afeta a autopercepção de competência e motivação para as atividades escolares. Esses aspectos estão associados a uma baixa auto-estima e à violência dentro das escolas. (CARDIA, 1997)
}

A experiência escolar marca profundamente a vida do adolescente, menos pelo conteúdo das disciplinas e mais por ser uma grande vivência de socialização, de convívio com as diferenças, um espaço no qual o aluno desenvolve (ou não) capacidades tais como ouvir, negociar, ceder, participar, cooperar, perseverar e lhe é oferecida a oportunidade de interagir com outros adultos e de identificar outros modelos de referência. Devido a essa importância, o fracasso escolar freqüentemente gera um processo de culpabilização e deterioração da auto-estima, com sentimentos de inferioridade por acreditar que, tendo fracassado na escola, fracassará também na vida. Dessa forma, tanto o insucesso escolar pode ser a causa de comportamentos agressivos, quanto a violência pode motivar o baixo desempenho acadêmico. Estudantes que evadem da escola burlam aulas ou têm uma auto-imagem acadêmica pobre apresentam maiores probabilidades de se engajarem em comportamentos violentos e de risco para sua saúde.

Embora a escola seja afetada pelo mesmo contexto histórico, social e moral e pela cultura de violência até aqui descritos, muitas vezes ela "coloca-se e é colocada como um espaço isolado da sociedade, distante 
dos seus problemas, desenvolvendo uma pedagogia que escamoteia o conflito, que impede que as contradições apareçam, uma pedagogia que nega a realidade e que prepara para um mundo que não existe, ou melhor, não prepara para o que existe". (COSTA, 1993)

Talvez decorra dessa alienação o fato de que 55,6\% das escolas públicas do país sofrem problemas de roubo, furto, vandalismo e/ou agressão ao patrimônio, no mínimo uma vez ao mês. O mesmo não ocorre "onde a participação na vida da escola é maior, onde se efetiva de algum modo a apropriação desse espaço público pela comunidade", comprovando que "é a carência de exercício da cidadania o que ameaça a escola" (UnB, 1999).

Segundo MINAYO et al. (1999), as instituições escolares apresentam três atitudes básicas em relação à violência: quando ocorre no âmbito doméstico, se omitem; quando cometida por aluno(s), reprimem; quando cometida por professor, minimizam ou acobertam.

\section{Buscando caminhos possíveis}

É necessário reconhecer que "muito pouco de prevenção à violência tem sido efetuada no Brasil" e que, "mesmo em países industrializados, as experiências são pontuais, carecendo de firmeza na definição das estratégias preventivas e freqüentemente não são avaliadas" (ASSIS, 1995). Tal fato se reflete tanto na literatura científica, conforme constatado por GOMES, SILVA, NJAINE (1999), quanto nas publicações leigas. A Pesquisa ANDI, que monitora a cobertura dos 52 principais jornais diários do Brasil a respeito da infância e adolescência, detectou, no período de julho a dezembro de 1998, que, dentre as 16 áreas temáticas analisadas, violência foi a quarta mais abordada, com aproximadamente 1.800 matérias. Entretanto, analisando-se o percentual de matérias consideradas "busca de soluções", este tema ficou em último lugar, com um percentual de $11,6 \%$, em comparação com uma média de $37,9 \%$.

Num contraponto positivo, a revista Nova Escola veiculou, em setembro/99, reportagem descrevendo iniciativas desenvolvidas por 13 escolas. "Nunca se falou tanto de violência nas escolas como neste ano. Inclusive - e isso é uma boa notícia - dentro das salas de aula". Foram relatadas estratégias como a reflexão sobre o Estatuto da Criança e do Adolescente, melhorias físicas e estéticas do prédio escolar, envolvimento dos pais na vida escolar, abertura da escola para as necessidades da comunidade, oficinas lúdicas e esportivas, processos de arte-educação, elaboração coletiva de normas de convivência, criação de "pelotões da paz" entre os estudantes, melhoria da relação professor-aluno com ênfase na afetividade, confiança e respeito, e punições alternativas para o aluno que transgride as regras.

É óbvio que, pela magnitude e complexidade do problema descrito, qualquer iniciativa em busca de soluções, por mais simples que seja, não pode ser reducionista. De acordo com MINAYO (1994), qualquer projeto de prevenção da violência passa por uma "articulação intersetorial, interdisciplinar, multiprofissional e com organizações da sociedade civil e comunitária que militam por direitos e cidadania. Sobretudo, há que atuar com uma visão ampla do fenômeno, mas em níveis locais e específicos".

Ao revisar os estudos inovadores no campo da redução da violência juvenil nas Américas, MCALISTER (1998) conclui que esta pode ser alcançada, a longo prazo, através da educação e da comunicação dirigidas à mudança de atitudes e ao desenvolvimento de habilidades, com as seguintes estratégias: (1) educação e terapia direcionados aos pais para melhorar as suas práticas na criação dos filhos; (2) educação e programas centrados nas escolas visando alterar os fatores ambientais (redução da disponibilidade de armas de fogo e outras; aumento da disponibilidade de reações não violentas; redução das desigualdades na qualidade de vida; modificar as conseqüências, de modo a punir a violência e premiar a não-violência); (3) programas comunitários que incluam escolas, meios de comunicação, organizações comunitárias e outros foros, num esforço para mudar atitudes, desenvolver habilidades e promover mudanças nas políticas sociais e nos ambientes.

Portanto, embora a prevenção da violência não seja atribuição ou domínio exclusivos de qualquer setor, tanto a Educação como a Saúde têm um papel preponderante a desempenhar. O impacto de tais programas será mais efetivo quanto maior for a cooperação entre os vários setores e atores sociais, cada qual assumindo sua parcela de responsabilidade num trabalho integrado que envolva crianças e adolescentes, seus pais e mães, as escolas, as associações e lideranças comunitárias, os grupos religiosos, os técnicos de Saúde, os policiais etc.

A importância da comunidade nesse processo não deve ser menosprezada, uma vez que "os crimes violentos estão associados a contextos onde há: a) desorganização social, entendida como pouca participação 
em atividades coletivas; b) pouca filiação a igrejas; c) muita mobilidade dos moradores; d) desemprego; e) forte densidade populacional". Por outro lado, quando os adolescentes são "bem integrados na vida da comunidade, aumenta a sensação de proteção, reduzindo-se a percepção de risco a despeito da ameaça real" (CARDIA, 1997).

\section{Conclusão}

A sociedade brasileira é permeada por uma inegável violência estrutural, manifesta em um quadro de injustiças sociais, disparidades econômicas, exclusão e falta de oportunidades que afeta a maioria da população. Esse estado de coisas, que se busca ocultar sob a aparência de naturalidade ou inevitabilidade, está na raiz de inúmeras modalidades de violência, mais fáceis de serem evidenciadas. Não obstante, é essencial que sejam dados passos concretos nos aspectos da realidade que estão ao nosso alcance imediato, ao mesmo tempo em que se luta por mudanças estruturais nos sistemas econômico, político e jurídico.

Se se deseja contribuir efetivamente para o desenvolvimento integral das gerações em formação, é preciso estar convicto da premência, necessidade e viabilidade do trabalho integrado, em nível dos microssistemas, em processos sistemáticos e permanentes de educação para a paz, para o respeito aos direitos humanos e à diversidade, e para os valores éticos universais. A adolescência, etapa crucial na formação da identidade, precisa ser aproveitada para que sejam ensinadas a resolução pacífica de conflitos e a inseparabilidade entre direitos e deveres na vida em sociedade.

Nessa busca de caminhos possíveis, o adolescente precisa ser reconhecido como um dos protagonistas. Enquanto ele for enxergado apenas como um problema ou o problema, será excluído da possibilidade de canalizar construtivamente suas energias como agente de transformação social.

\section{REFERÊNCIAS}

ADORNO, S. Conflitualidade e violência: reflexões sobre a anomia na contemporaneidade. Tempo Social; Ver. Sociológica. São Paulo, v. 10, n. 1, maio 1998.

ASSIS, S. G. Trajetória sócio-epidemológica da violência contra crianças e adolescentes: metas de prevenção e promoção. Rio de Janeiro, 1995. Tese (Doutorado) - Fundação Oswaldo Cruz.

Crianças e adolescentes violentados: passado, presente e perspectivas para o futuro. Cadernos de Saúde

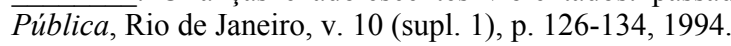

AZEVEDO, M. A.; GUERRA, V. N. A. (Org.). Infância e violência doméstica: fronteiras do conhecimento. 2. ed. São Paulo: Cortez, 1997.

BASTOS, A. C. S. Modos de partilhar a inserção da criança na vida cotidiana da família: um estudo comparativo de casos. Brasília, 1994. Tese (Doutorado) - Instituto de Psicologia, Universidade de Brasília.

BRONFENBRENNER, U. A ecologia do desenvolvimento humano: experimentos naturais e planejados. Porto Alegre: Artes Médicas, 1996.

CARDIA, N. A violência urbana e a escola. Contemporaneidade e Educação, ano 2, n. 2, set. 1997.

CHESNAIS, J. C. A violência no Brasil: causas e recomendações políticas para a sua prevenção. Ciência \& Saúde Coletiva, v. 1, n. 4, p. 53-69, 1999.

COSTA, A. C. G. Protagonismo juvenil: adolescência, educação e participação democrática. Fundação Odebrecht, 1999. Mimeog.

COSTA, H. H. A trama da violência na escola. Rio de Janeiro, 1993. Dissertação (Mestrado) - Fundação Getúlio Vargas.

COSTA, J. F. O medo social: reflexões para o futuro. Veja 25 Anos, p.83- 89, 1993.

DONAS, S. Marco Epidemiológico-Conceptual da Saúde Integral do Adolescente. Organização Pan-Americana da Saúde. Brasil, 1992.

ERIKSON, E. H. Identidade, juventude e crise. 2. ed. Trad. de: Álvaro Cabral. Rio de Janeiro: Zahar, 1976. 
ESTATUTO DA CRIANÇA E DO ADOLESCENTE, 1989.

FERREIRA, M. G. M.; STEINER, M. H. F. Mulheres espancadas - e seus filhos? In: STEINER, M. H. F. (Org.). Quando a criança não tem vez. São Paulo: Pioneira, 1986.

GIFFIN, K. Violência de gênero, sexualidade e saúde. Cadernos de Saúde Pública, Rio de Janeiro, v. 10 (supl. 1), p.146$155,1994$.

GOMES, R.; SILVA, C. M. F. P.; NJAINE, K. Prevenção à violência contra a criança e o adolescente sob a ótica da saúde: um estudo bibliográfico. Ciência \& Saúde Coletiva, v. 1, n. 4, p. 171-181, 1999.

IBGE. Crianças e adolescentes: indicadores sociais. Rio de Janeiro: IBGE, 1989. v. 4.

JUNQUEIRA, E. A geração da onda. Veja, p. 84, 24 set. 1997.

McALISTER, A. Juvenile violence in the Americas: innovative studies in research, diagnosis and prevention. Pan American Health Organization, 1998.

MESQUITA, M. Homicídios de crianças e adolescentes: uma contribuição para a administração da justiça criminal em São Paulo. In: ESTADO DE SÃO PAULO. Ministério Público/UNICEF. Relatório de Pesquisa Aplicada. São Paulo, 1995. Mimeog.

MILANI, F. M. O adolescente, a família e a escola: uma visão integrada. CONGRESSO NACIONAL: A SAÚDE DO ADOLESCENTE (1.: 1991: Rio de Janeiro). Anais... Rio de Janeiro: Academia Nacional de Medicina, 1991. p. 389 - 402. set.1995.

O adolescente, a escola e a família: um sistema integrado. CEAP - Revista de Educação, Salvador, n. 10, jan./fev. 1998.

Adolescente, escola e sociedade rumo à maturidade. Dois Pontos - Teoria e Prática em Educação, v. 4, n. 36,

MINAYO, M. C. S. A violência social sob a perspectiva da Saúde Pública. Cadernos de Saúde Pública, Rio de Janeiro, v. 10 (supl. 1), p. 07-18, 1994.

ENSP, $1990.168 \mathrm{p}$

(Coord.). Bibliografia comentada da produção científica brasileira sobre violência e saúde. Rio de Janeiro:

et al. Juventude, violência e cidadania. Rio de Janeiro: Garamond, 1999. 238 p.

; SOUZA, E. R. É possível prevenir a violência? Reflexões a partir do campo da Saúde Pública. Ciência \& Saúde Coletiva, v. 1, n. 4, p. 7-32, 1999.

MINISTÉRIO DA SAÚDE. Violência contra a criança e o adolescente: proposta preliminar de prevenção e assistência à violência doméstica. Brasília, 1997. 24 p.

NETO, O. C.; MOREIRA, M. R. A. Concretização de políticas públicas em direção à prevenção da violência estrutural. Ciência \& Saúde Coletiva, v. 1, n. 4, p. 33-52, 1999.

NOVA ESCOLA, ano 14, n. 125, set. 1999.

NUNES, E. D. Debatedores: é possível prevenir a violência? Reflexões a partir do campo da saúde pública. Ciência e Saúde Coletiva, v.1, n. 4, p. 24-25, 1999.

OPAS. O marco conceptual da saúde integral do adolescente e de seu cuidado. Washington, 1990. Mimeog.

Violencia contra la mujer: un tema de salud prioritario. Washington, 1998.

OSÓRIO, L. C. Adolescente hoje. Porto Alegre: Artes Médicas, 1989. 103 p.

PAIM, J. S.; COSTA, M. C. N. Mortes violentas em crianças e adolescentes de Salvador. Bahia Análise e Dados, Salvador, v. 6, n. 1, p. 59-67, jun. 1996.

PESQUISA ANDI - INFÂNCIA NA MÍDIA, ANDI/ Instituto Ayrton Senna/UNICEF, jul./dez. 1998.

PROGRAMA NACIONAL DE PAZ NAS ESCOLAS. Resumo sintético. 1999. Mimeog.

PROJETO ACTIVA. OPAS/ UFBA/UNEB. 1997.

SAFFIOTI, H. I. B. A síndrome do pequeno poder. In: AZEVEDO M.; GUERRA, V. N. A. Crianças vitimizadas: a síndrome do pequeno poder. São Paulo: IGLU, 1989. p. 13-21. 
SCHRAIBER, L. B.; D'OLIVEIRA, A. F. L. P. Violência contra mulheres: interfaces com a saúde. INTERFACE Comunicação, Saúde, Educação, v. 3, n. 5, p. 11-26, 1999.

SPENCER, M. B. Old issues and new theorizing about african-amerian youth: a phenomenological varient of ecological systems theory. In: TAYLOR (Ed.) African-american youth: their social and economic status in the United States. Westport, CT: Praeger, 1995.

UnB/INSTITUTO DE PSICOLOGIA/LABORATÓRIO DE PSICOLOGIA DO TRABALHO. Segurança nas Escolas Públicas. Brasília, 1999.

U.S. DEPARTMENT OF JUSTICE. Criminal victimization in the United States, 1986: A National Crime Survey Report. Washington, D.C.: (NCJ-111456), 1988.

WAISELFISZ, J. Mapa da violência: Os jovens do Brasil. Juventude, violência e cidadania. Rio de Janeiro: Garamond, 1998. 136p.

. Juventude, violência e cidadania: os jovens de Brasília. São Paulo: Cortez, 1998.

YUNES, J.; RAJS, D. Tendencia de la mortalidad por causas violentas en la población general y entre los adolescentes y jóvenes de la région de las Américas. Cadernos de Saúde Pública, Rio de Janeiro, v. 10 ( supl. 1); p. 88-125, 1994.

ZALUAR, A. Teleguiados e chefes: juventude e crime. In: RIZZINI, I. (Org.) A criança no Brasil hoje. Rio de Janeiro: Editora Universitária Santa Úrsula, 1993. 